\begin{tabular}{l|l}
\hline SISTEMA \\
ELEÔNICO \\
DE REVISTAS \\
SER I UFPR
\end{tabular}

\title{
Ambiente urbano, desigualdades socioeconômicas e saúde: o papel da história e o espaço da ação social*
}

\author{
Claude RAYNAUT ${ }^{1}$, Angela Duarte Damasceno FERREIRA ${ }^{2}$ \\ ${ }^{1}$ Antropólogo, Doutor em Antropologia, directeur de recherche au Centre National de la Recherche Scientifique, Universidade de Bordeaux 2 \\ Victor Segalen, França \\ ${ }^{2}$ Socióloga, Doutora em Sociologia, professora do Departamento de Ciências Sociais da UFPR
}

Como em toda pesquisa e ainda mais em trabalhos pioneiros no domínio da interdisciplinaridade, os resultados deste programa têm seus limites. A problemática comum que norteava e articulava as pesquisas individuais não logrou abranger todas as questões essenciais que poderiam se colocar diante do fenômeno da urbanização acelerada e das suas consequências não só para o ambiente considerado em si mesmo, mas também para as condições materiais e sociais de existência de seus habitantes - questões fundamentais para o Brasil de hoje. Além disso, algumas das pesquisas de tese inicialmente previstas não foram realizadas dentro do quadro de prioridades estabelecidas pelo programa ou não se desenvolveram de forma a garantir o diálogo desejável para garantir os resultados esperados de um processo de pesquisa interdisciplinar.

Não obstante, a análise da realidade parnanguara à qual chegamos, por incompleta que seja, representa um avanço significativo tanto do ponto de vista do conhecimento empírico desta realidade como enquanto experiência metodológica. Ela traz também elementos pertinentes para alimentar uma reflexão teórica sobre o papel da saúde como revelador da dinâmica das relações que os moradores das cidades mantêm com seu ambiente de vida. Um outro livro está sendo preparado para apresentar em detalhes os resultados destas pesquisas mais específicas. Por isto, vamos apontar aqui apenas algumas das suas conclusões que consideramos particularmente importantes, sem desenvolvê-las de modo aprofundado.

Cabe salientar que os capítulos deste livro apresentam algumas das conclusões das teses que eles resumem. Para apreender toda a riqueza de seu conteúdo, o leitor deve imperativamente lê-las na íntegra.

\footnotetext{
* Publicado originalmente em: Raynaut, C. et al. (Eds.). Desenvolvimento e meio ambiente: em busca da interdisciplinaridade: pesquisas urbanas e rurais. Parte I, Capítulo 7. Curitiba: Ed. da UFPR, 2002. p. 127-136.
} 


\section{A diversidade da trama urbana: o papel da história}

Um dos primeiros objetivos do trabalho de pesquisa, durante a fase coletiva, foi a descrição e a análise das heterogeneidades da trama urbana. Para cumprir tal tarefa, a opção metodológica adotada, facilitada pelo tamanho de porte médio da cidade, foi de não usar o recorte preestabelecido da classificação de bairros. Preferiu-se empreender um zoneamento que fosse o resultado de critérios de descrição objetivos, tomando como unidade de caracterização o quarteirão e o recorte das zonas resultando da agregação de quarteirões apresentando características semelhantes. Conforme apresentado no capítulo 1, dois grupos de variáveis foram utilizados:

- variáveis relativas ao crescimento e adensamento da aglomeração urbana, com o perfil das funções urbanas, analisadas a partir de fontes estatísticas, cartográficas e fotografias aéreas e através da observação direta: cronologia do crescimento espacial, reconstituída a partir dos mapas e de fotografias aéreas $(1953,1970,1985,1994)$; densidade demográfica, verificada pelos dados censitários (Censo Demográfico 1991, IBGE); funções urbanas, diretamente observadas no campo;

- outras foram construídas pelo cruzamento de indicadores empíricos: nível de vida da população residente, avaliado através do tipo dominante de moradia em cada quarteirão (resultado ele mesmo de um levantamento direto no campo), do valor imobiliário (Plano Municipal de Habitação, Prefeitura de Paranaguá) e do nível de consumo de energia elétrica (Copel, Diretoria de Distribuição); nível de saneamento, avaliado através das ligações de água e da densidade de instalações sanitárias (Censo Demográfico 1991).
No momento de se fazer a síntese dos vários mapas assim construídos, ficou claro que a variável que permitia melhor ordenar a diversidade da distribuição das outras era a cronologia de crescimento de Paranaguá, tal como se materializava na ocupação do espaço. É nos bairros mais antigos, situados no centro da cidade, que se concentram as feições mais favoráveis da trama urbana: equipamentos e serviços (escolas, hospitais, comércios), valor da moradia e nível de saneamento. Ao mesmo tempo, a qualidade do quadro material de vida vai diminuindo do centro para a periferia.

Esse crescimento, por sua vez, foi o reflexo do ritmo acelerado do crescimento populacional da cidade (Figura 1).

Esta dinâmica demográfica foi uma repercussão, direta e indireta, de um fator dominante: a evolução das atividades do porto. Durante as duas décadas 50 e 60, estas se desenvolveram a um ritmo muito rápido, consequência da expansão da produção do café no Norte do Estado. Em 1965, o porto de Paranaguá conquistou o título de maior exportador do mundo (vide Godoy). A partir dos anos 70, a produção do café no Paraná foi substituída pela produção de grãos, especialmente a soja, dando um novo impulso às atividades portuárias. A modernização tecnológica do porto, a partir dos anos 80 , gerou uma redução muito forte do número de empregos diretos nas atividades portuárias. Esta redução foi compensada pelo desenvolvimento do setor industrial e de serviços fomentados pela presença do porto. Em consequência, o número total de empregos em Paranaguá cresceu 42\% entre 1960 e 1980 (vide Godoy).

Enquanto polo de empregos e como fator de dinamismo para a economia de Paranaguá, o porto atraiu populações migrantes que contribuíram para o crescimento demográfico significativo registrado na cidade. A enquete domiciliar realizada em 1996 


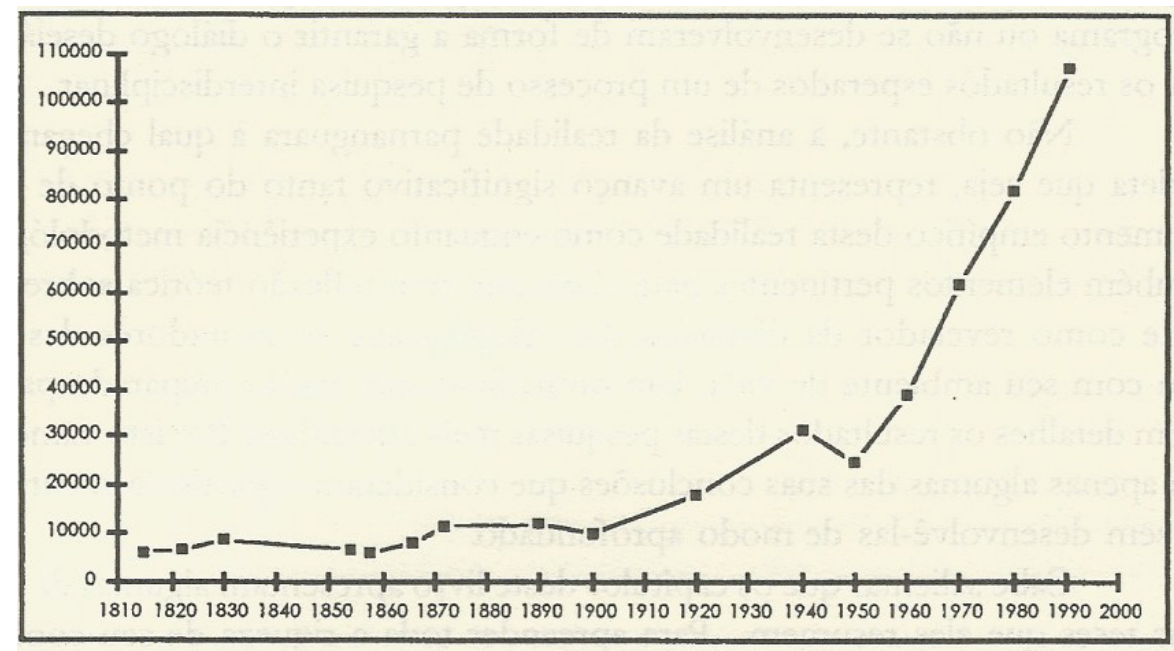

FIGURA 1 - Evolução da população do município de Paranaguá de 1815 a 1991

mostrou que cerca de $48 \%$ dos chefes de família nasceram fora da cidade (Gerhardt; Nazareno; Novakoski, 1997: 27). Eles eram nascidos em outros municípios do litoral paranaense $(14,7 \%)$ - cujas comunidades agrícolas e pesqueiras enfrentam, desde meados do século XX, uma profunda crise econômica - mas também em outros municípios do Paraná (16\%) e em vários estados vizinhos ou mais longínquos (16,8\%). Numa primeira etapa, a extensão da aglomeração fez-se para o noroeste do centro urbano, resultado do deslocamento oficial do porto do rio Itiberê para a baía, em 1935. Até hoje, as atividades, a organização espacial desta área, seu ambiente, bem como a estrutura de sua população, são fortemente marcados pela proximidade do porto. Mas, a partir dos anos 60 , quando este espaço alcançou alta densidade demográfica, as populações que continuavam chegando, geralmente de baixa renda, não conseguindo mais se estabelecer ali, começaram a buscar novas áreas para se instalarem, afastando-se rapidamente do centro e da zona portuária ao longo da estreita faixa de terra situada entre os rios Itiberê e Emboguaçu. Iniciaram, também, a ocupação das áreas de mangue, na beira da baía e dos rios (vide Caneparo). A Ilha de Valadares, que já abrigava algumas comunidades de pescadores, passou a ser ocupada intensamente e por uma população mais diversificada.

É ao decorrer desta história econômica e demográfica que se formou a fisionomia atual da cidade, de modo que existe hoje uma correspondência estreita entre a cronologia de ocupação das várias zonas e as feições que elas apresentam, tanto do ponto de vista do quadro de vida que proporcionam a seus moradores quanto das características sociais e econômicas destes (vide Raynaut \& Ferreira, capítulo 1).

O que estas diferenças expressam - além da evidente apropriação dos espaços da cidade com melhor quadro de vida pelos que têm melhores níveis socioeconômicos - é a incapacidade dos responsáveis pelos vários setores da política urbana para responder adequadamente aos desafios criados por um crescimento populacional extremamente rápido. Se, como Godoy mostra de modo convincente, não aconteceu em Paranaguá o mesmo divórcio que 
se observou, em muitos portos do mundo, entre atividades portuárias e o tecido urbano, vivenciou, não obstante, uma nítida desvinculação entre o polo de dinamismo e de arrecadação de recursos, que constituíram as atividades portuárias e a modernização da cidade, de seus equipamentos e de sua trama material e social. Ao lado de um dos portos mais ativos e hoje mais modernos do Brasil, Paranaguá permanece uma cidade um tanto adormecida, com infraestruturas padecendo de um indiscutível atraso e onde permanecem espaços que oferecem a seus moradores um ambiente de vida extremamente precário. As pesquisas conduzidas no domínio da saúde permitiram avaliar os desdobramentos desta situação sobre o corpo das crianças (vide Gerhardt \& Nazareno, capítulo 6) e o trabalho feito com crianças nas escolas da cidade (vide Carneiro, capítulo 4) mostra suas consequências no que diz respeito às representações que a nova geração tem sobre seu ambiente de vida.

\section{As desigualdades econômicas: flexibilidade e complexidade de uma projeção espacial}

A história migratória que constitui o fio condutor dos processos de diferenciação do espaço urbano parnanguara desdobra-se, no domínio social e econômico, em desigualdades que dividem a população urbana. A estratificação realizada a partir dos dados da enquete domiciliar (vide capítulo 1) distingue três categorias, que se diferenciam nitidamente em função de suas condições materiais de vida:

- O estrato inferior $(27,7 \%)$ caracteriza-se por suas condições de moradia muito precárias: em muitos casos barracas feitas de tábuas mal juntadas, sem forro, se beneficiando apenas de água encanada mediante ligações clandestinas e sem instalações sanitárias adequadas. Frequentemente, famílias numerosas avultam-se num espaço reduzido, resul- tando numa densidade habitacional alta. A posse de bens de consumo duráveis é muito reduzida (sendo a geladeira o bem básico que $85 \%$ das famílias deste estrato possuem, bem como o rádio e, em proporção inferior, a televisão). O nível de escolaridade dos chefes de família é baixo (em 58\% dos casos, é igual ou inferior a 4 anos de estudo - proporção na qual entram 20\% de analfabetos);

- O estrato médio (37,6\%) apresenta globalmente condições materiais de vida melhores: ambiente habitacional mais saudável (tanto do ponto de vista da qualidade da construção como do seu tamanho e de seu equipamento sanitário); posse mais frequente de bens para o aumento do conforto doméstico (televisão a cores: 92\%; máquina de lavar roupa: 56\%); uma pequena minoria chega a ter carro (11\%). Os chefes de família têm um nível de escolaridade expressivamente melhor, sendo que apenas 2,5\% deles são analfabetos;

- As famílias do estrato superior $(33,8 \%)$ moram quase todas em condições que cumprem os requisitos essenciais das exigências sanitárias, do bem-estar e do conforto. Quase todos os domicílios são amplamente equipados em bens domésticos e todos possuem um carro (muitas vezes dois). O nível de escolaridade dos chefes de família é caracterizado pelo fato de que uma proporção significativa deles (48\%) tem mais de nove anos de estudos.

Apesar de ser aproximativa, essa estratificação dá, a respeito das realidades socioeconômicas da população parnanguara, uma imagem que pode alimentar uma reflexão sobre os processos geradores de desigualdades. Quase um terço dos habitantes da cidade padece de condições materiais de existência muito precárias, potencialmente prejudiciais tanto para seu bem-estar como para sua saúde. A análise da relação entre estas disparidades socioeconômicas e os fluxos migratórios que alimentaram o crescimento rápido de Paranaguá não autorizam simplificações: 
a chegada de migrantes não contribuiu de forma claramente diferenciada à formação da faixa mais carente da população urbana. Os estratos médio e baixo apresentam uma proporção igual de chefes de família nascidos em Paranaguá (41,5\%). No caso do estrato alto, a percentagem é mais alta (58\%), sugerindo que os autóctones desfrutam uma certa "renda de situação". No entanto, esta distribuição não dá conta do fato de que uma parcela tão importante da população se situe às margens da vida social e econômica da cidade. Ou seja, contrariando as perspectivas de análise que atribuem a marginalização da população urbana às migrações, especialmente às rurais-urbanas, em Paranaguá este mecanismo de marginalização não acomete os que vieram de fora, mas aplica-se também aos que nasceram na cidade. Uma análise mais fina precisaria, sem dúvida, levar em conta ao menos duas gerações de moradores, já que os filhos de migrantes, apesar de terem nascido em Paranaguá, podem encontrar dificuldades maiores do os filhos dos autóctones para melhorar seu nível de vida. No entanto, parece indiscutível a existência de mecanismo de diferenciação internos que se aplicam à população urbana como um todo, incluindo-se migrantes e não migrantes.

Esses mecanismos são claramente ligados ao mercado do trabalho tal como ele se organiza em Paranaguá: dominado de maneira direta ou indireta pelo porto. Uma das variáveis que diferencia mais os estratos entre si é o nível de desemprego ou subemprego dos chefes de família e dos outros membros da família. É claramente a capacidade de acesso ao mercado do trabalho e as condições da inserção nele que constituem o principal fator que determina a posição das famílias na escala socioeconômica. Isto não diferencia a cidade de outras regiões submetidas ao mesmo tipo de organização societária. Mas, sua singularidade reside no papel central que o porto desempenha na oferta de trabalho e na na- tureza das relações de trabalho mantidas com ele. Como se pode observar pelos dados apresentados por Godoy, $45 \%$ dos chefes de família do estrato superior que têm emprego exercem um trabalho direta ou indiretamente ligado ao porto; dentro do estrato inferior, a proporção cai a $31 \%$.

Um outro caráter discriminador entre os estratos reside na formalidade ou informalidade do trabalho (manifestando-se no fato de ter ou não uma carteira de trabalho ou de ser dono de uma empresa oficialmente declarada). Enquanto $84 \%$ dos chefes de família do estrato superior exercem uma atividade formal, isto é o caso para apenas $52 \%$ dos chefes de família do estrato inferior.

Em resumo, poder desfrutar do benefício do dinamismo econômico gerado pela presença do porto e poder ter acesso a um emprego formal são fatores que participam de maneira determinante do processo de diferenciação socioeconômica que se aplica à sociedade parnanguara. $\mathrm{O}$ fato de ter nascido em Paranaguá pode facilitar tal inserção - especialmente para as faixas sociais mais bem-sucedidas - mas nunca constitui um privilégio que proteja os autóctones dos mecanismos de exclusão e marginalização que atualmente vêm se exercendo, de forma crescente, no mercado do trabalho.

Como se viu acima, dois tipos de recorte diferentes foram utilizados para exprimir as heterogeneidades e as desigualdades que, em Paranaguá, dividem o espaço urbano e o conjunto de seus habitantes. Por um lado, a divisão em subespaços distintos: as zonas que proporcionam ambientes de vida quotidiana nitidamente diferentes para seus moradores. Por outro lado, estratos que hierarquizam as famílias parnanguaras em função do seu nível socioeconômico. Claro que os dois recortes têm correspondências entre si. Conforme indicado no capítulo1 (Figura 5), existe uma relação linear entre as características das zonas e o nível econô- 
mico médio da sua população residente. Mais de $85 \%$ das famílias que moram nas zonas do centro urbano e da expansão portuária pertencem aos dois estratos superiores. Na zona de expansão recente, os três estratos se repartem em proporções quase iguais, enquanto as famílias do estrato inferior são as mais numerosas nas "franjas" ou áreas periféricas e na ilha de Valadares.

De modo geral, como se podia esperar, as famílias com poder aquisitivo mais alto se concentram nas áreas que oferecem condições de moradia mais convenientes e uma melhor oferta de serviços. Esta observação não tem nada que possa surpreender! Simples manifestação espacial das disparidades socioeconômicas. Contudo, nenhuma zona evidencia-se como totalmente homogênea fato que conduz a uma reflexão mais nuançada sobre a complexidade das relações entre desigualdades sociais e meio ambiente: encontram-se famílias bem abastadas nas zonas que apresentam péssimas características e famílias carentes nas áreas do centro da cidade. Isso pode remeter parcialmente a certas imprecisões quanto ao traçado dos limites das zona s ou à definição dos estratos, mas, antes de tudo, constitui a manifestação de estratégias deliberadas desempenhadas por essas famílias: tome-se como exemplo, entre muitos outros que a pesquisa qualitativa pôde revelar, a procura de independência em relação a seus pais, no caso das gerações mais jovens das famílias do estrato superior, buscando terrenos mais baratos nas áreas menos valorizadas da cidade; ou o desejo de se aproximar das infraestruturas de serviços básicos (saúde, educação) e das áreas onde trabalham, no caso de famílias carentes que se instalam nas zonas centrais, cujo padrão ambiental e habitacional globalmente alto não deixa de incluir espaços "intersticiais" (terrenos ainda não urbanizados, casas ou apartamentos velhos de baixo padrão ou mal cuidados) onde podem morar.
Isso mostra os limites dos instrumentos de ampla escala e de tipo quantitativo para a caracterização e descrição de um espaço coletivo ou de uma população. Atrás das tendências gerais, e por pertinentes que sejam elas, sempre há lugar para dimensões mais singulares da realidade e para formas de desempenho de caráter mais individual. As heterogeneidades da trama urbana, bem como os mecanismos socioeconômicos geradores de desigualdades, constituem um quadro geral que vem se impondo aos habitantes da cidade, orientando, viabilizando ou limitando sua capacidade de conduzir a própria existência, de participar na elaboração do seu ambiente de vida. Não obstante, a determinação nunca é mecânica e direta: sempre sobra espaço para a atuação dos atores sociais ou para o efeito inesperado dos eventos: busca de solução para os problemas encontrados, estratégias de promoção social e desenvolvimento de projetos de vida, mas também situações geradoras de risco e de vulnerabilidade (doenças, conflitos, estresses, etc.) que expõem até as famílias mais bem-sucedidas a episódios de regressão na trajetória de sua existência. É essa visão dinâmica das disparidades e das desigualdades urbanas que os resultados dos estudos mais voltados para questões de saúde também reforçaram.

\section{Meio ambiente e saúde: o papel das situações de vida}

Três teses dedicaram-se, a partir de pontos de vista disciplinares diferentes, ao estudo das relações entre desigualdades econômicas, disparidades nas condições materiais de vida e saúde. Duas delas colocaram a questão a partir das perspectivas saúde pública e da epidemiologia. Uma outra desenvolveu uma abordagem antropológica. Esses três trabalhos foram conduzidos de maneira estreitamente ligada, tanto que os resultados dos estudos epidemiológico e 
antropológico são apresentados, aqui, dentro de um só capítulo (vide Gerhardt \& Nazareno, capítulo 6).

Os resultados destas pesquisas evidenciam, em primeiro lugar, a existência de uma forte relação entre, de um lado, o quadro de vida material destas famílias em função de sua zona de residência e do estrato socioeconômico ao qual elas pertencem e, de outro, o seu nível e tipo de acesso aos serviços de saúde e o estado de saúde de suas crianças. Isso não constitui, de modo nenhum, um achado original - muitos são os estudos que já mostraram as consequências das desigualdades sociais sobre a saúde das populações urbanas. No entanto, esses resultados vêm confirmar a pertinência dos instrumentos pelos quais tentamos descrever as disparidades de condições de vida que se observam em Paranaguá.

Globalmente considerada, a oferta de saúde em Paranaguá caracteriza-se pela insuficiência de leitos hospitalares e a deficiência dos serviços de saúde públicos (vide Novakoski, capítulo 5). Hospitais privados são bem mais equipados e estruturados, porém, atendem exclusivamente particulares, planos e convênios de saúde. O único hospital geral que atende pelo Sistema Único de Saúde apresenta construção comprometida e obras paralisadas; instalações precárias; falta de manutenção e escassez de recursos. Além disso, a distribuição espacial dos serviços de saúde é heterogênea, apresentando grande concentração no centro da cidade e deixando as zonas mais periféricas sem serviços suficientes para atender as necessidades de sua população. A evolução histórica da cidade e seu crescimento espacial e populacional não foram acompanhados da criação de uma infraestrutura adequada de redes e serviços essenciais. Nessas condições, a população utiliza os serviços públicos, particulares, planos e convênios de saúde, de acordo com sua posição geográfica no espaço urbano e conforme seu estrato socioeconômico.
Como indicado também no mesmo capítulo, a zona denominada "Centro Urbano" destaca-se pela utilização majoritária do atendimento em consultórios médicos, clínicas e serviços de sindicatos e empresas. Nas zonas de "Expansão Portuária" e de "Expansão recente" predomina a utilização da rede pública de saúde, centro e postos de saúde, centro de especialidades e pronto-socorro. Nas "Franjas Insalubres", a grande maioria das famílias depende exclusivamente da rede pública, enquanto na Ilha dos Valadares, ainda que mais de dois terços utilizem o serviço público, um quinto das famílias tem acesso a consultórios, clínicas e serviços de sindicatos e empresas.

Confirmam-se, igualmente, grandes desigualdades entre os estratos a respeito dos tipos de serviços utilizados: o estrato superior utiliza maciçamente $\mathrm{o}$ atendimento em consultórios, clínicas, serviços de sindicatos, hospitais privados do Município e de outras localidades; o estrato médio situa-se numa posição intermediária entre o público e o privado; a grande maioria $(91 \%)$ da população do estrato inferior utiliza o serviço público, postos ou centros de saúde, centro de especialidades e pronto-socorro.

No que diz respeito à acessibilidade econômica, as diferenças entre as zonas e entre as categorias socioeconômicas são também muito marcadas. Sendo que menos da metade das famílias estudadas possui plano ou convênio de saúde, a proporção alcança 70,5\% no "Centro Urbano", enquanto as demais zonas apresentam percentuais significativamente inferiores. A posse de plano ou convênio de saúde, quando analisada por estratos sociais, revela uma diferença de 61.5 pontos percentuais entre o estrato superior e o inferior.

As consequências das diferenças de ambiente de vida material, de nível econômico e de acesso aos serviços de saúde manifestam-se também nas condições de saúde das crianças - consideradas como população -, testemunhas da situação sanitária da 
sua família (vide Gerhardt \& Nazareno, capítulo 6). Três critérios principais foram utilizados para avaliar o estado de saúde das crianças em relação com seu ambiente de vida. Em primeiro lugar, as doenças de pele e as infecções parasitárias, enquanto manifestações do risco associado às condições de salubridade deste ambiente e à eficiência das medidas de higiene tomadas pelas famílias. Em segundo lugar, o estatuto nutricional, como resultado da capacidade das famílias de proporcionar a suas crianças uma alimentação adequada, tanto em quantidade como em qualidade.

No que diz respeito aos dois primeiros tipos de doenças, duas observações principais destacam-se. Primeiro, o nível globalmente alto da prevalência: $55,5 \%$ das crianças estudadas possuem doenças de pele e 55,8\% uma parasitose intestinal. Sem apresentar um caráter direto de gravidade, a frequência destas doenças não deixa de apontar para certas deficiências na situação sanitária das crianças que moram em Paranaguá: sugerem tanto um alto nível de risco associado ao ambiente urbano (falhas nas condições de saneamento) como insuficientes cuidados de higiene no espaço doméstico e medidas inadequadas de prevenção e de atendimento nas estruturas públicas frequentadas pelas crianças (escolas, postos de saúde).

Contudo, dentro deste quadro geral, estas patologias acometem de maneira muito diferenciada os vários grupos da população, conforme a zona de moradia e a categoria econômica a que pertencem. O risco de uma criança contrair uma doença de pele é duas vezes maior se ela mora nas zonas periféricas ou pertence ao estrato mais baixo. No caso das parasitoses intestinais, o fator multiplicador evidencia-se ainda mais alto: 14 vezes, segundo as zonas, e 6, segundo os estratos.

Para os dois tipos de patologias, o nível de risco é claramente associado às desigualdades econômicas, crescendo com o nível de pobreza e, então, com a falta de higiene encontrada no espaço domiciliar.
Mas, no que diz respeito às parasitoses, as condições de saneamento da zona de moradia, quer dizer do ambiente peridomiciliar, parecem desempenhar um papel ainda mais determinante; isto remete diretamente às políticas públicas de equipamento e manejo do espaço urbano. A prosperidade econômica do porto não se desdobra no nível de qualidade de vida oferecida aos habitantes da cidade.

Encontra-se uma realidade muito mais nuançada e complexa no que diz respeito aos dados nutricionais. A prevalência global de desnutrição crônica em Paranaguá é alta, enquanto a da desnutrição aguda é baixa. No que diz respeito às diferenças entre as categorias de população em função do seu local de moradia (zona), bem como do seu nível econômico (estrato), a análise não conduz a conclusões tão claras como aquelas relativas às patologias previamente analisadas. Embora se observe um aumento do nível de prevalência da desnutrição crônica em função da piora da situação econômica das famílias ou do ambiente das zonas onde elas moram, as diferenças observadas não são estatisticamente significativas quando se aplica um teste de comparação de frequências. Contudo, este resultado pode ser ligado ao tamanho insuficiente da amostra para estes fins, ocasionando a relativa escassez do fato observado. No que diz respeito ao risco nutricional (que mede o risco de uma criança - cujas características nutricionais estão, no quadro de estudo, dentro dos limites da "normalidade" - passar, no futuro, por um episódio de desnutrição), ele cresce em função da queda tanto da qualidade de vida na zona de moradia como do nível econômico da família.

A existência de uma relação entre as condições de vida materiais e econômicas que uma família experimenta e o estatuto nutricional das crianças não passa de um achado previsível. Mas, além de sua confirmação na realidade parnanguara, há de se considerar um fato muito significativo: 
seja qual for a vulnerabilidade das famílias mais pobres, morando nas zonas mais desfavorecidas da cidade, a taxa de desnutrição aguda de suas crianças permanece muito baixa. Isto indica que estas famílias desenvolvem estratégias de resposta que lhes permitem proteger suas crianças e evitar que ultrapassem o limite entre uma situação de risco nutricional e uma desnutrição declarada.

Tal observação salienta a pertinência de uma análise detalhada das práticas concretas adotadas pelas famílias para cuidar da saúde das suas crianças e para resolver os problemas que encontram neste domínio. Este foi o objetivo dos estudos antropológicos conduzidos nas mesmas famílias, em articulação com as enquetes epidemiológicas. Tais estudos (vide Gerhardt \& Nazareno, capítulo 6) evidenciaram, por parte das famílias pobres, a existência de estratégias de acesso aos recursos alimentares tais como integração a redes de circulação e distribuição de comida e outras formas de busca de proteção social. Nesta perspectiva, o papel principal é desempenhado pelas relações familiares e de vizinhança, a integração a redes de solidariedade organizadas em torno das igrejas, a integração dentro de redes sociais e políticas de clientelismo podem dar acesso às cestas básicas.

Num sentido contrário, certas famílias mais abastadas privilegiam estratégias de acesso fundiário (possibilidade de compra de terrenos maiores a preço mais barato) que as conduzem a morar nas zonas mais precárias da cidade, expondo potencialmente seus filhos a riscos em relação à saúde - em particular a doenças de pele, a parasitoses intestinais (que se situam, nestas zonas, acima do nível de prevalência na população total da cidade), bem como a dificuldades no acesso aos cuidados de saúde. As famílias do estrato superior que se instalam na zona de Franjas ou na Ilha de Valadares desenvolvem estratégias específicas para proteger seus filhos destes riscos (cuidados particulares do ambiente peridomiciliar, planos de saúde) mas nem sempre conseguem isto. Então, eles têm que buscar sempre uma conciliação entre seus objetivos socioeconômicos gerais, expressão da maneira como eles querem construir seu futuro, e os cuidados que eles têm em relação com a saúde das suas crianças e deles próprios.

Tais observações conduzem a questionar a noção de "condições de vida" considerada nas suas relações com as disparidades de saúde. Sem dúvida, cada indivíduo, cada família, cada grupo local, enfrenta, na sua existência quotidiana, não apenas restrições e potencialidades referentes a seu quadro de vida material, mas também aquelas que se originam em seu universo social e cultural: representações e valores transmitidos pela educação e pelos processos de socialização; configuração de relações interpessoais decorrentes da organização social e dos embates de poder. Seu estado de saúde está, necessariamente, sob a dependência deste contexto, refletindo a posição que ele ocupa dentro da estrutura social e econômica da sociedade. No entanto, cada um - indivíduo, família, grupo local - conserva um espaço de atuação própria, que lhe permite intervir como ator da sua própria existência, reinterpretando as condições externas às quais ele é submetido e elaborando o que nós propomos chamar de "situação de vida": essa realidade existencial quotidiana à qual ele impõe, com mais ou menos força conforme os casos, o seu cunho. Ele elabora assim, no decorrer da sua história pessoal, sua própria experiência de sujeito: consciência e olhar distanciado sobre o que cabe em torno dele, do domínio do material como do imaterial.

Qual é o interesse desse tipo de observação em termos de orientação para as ações de saúde? Poderia se dizer que se trata aqui de estratégias de sobrevivência desenvolvidas pelas camadas sociais mais carentes e de estratégias de realização da vida 
cotidiana e de promoção pessoal adotadas pelas famílias favorecidas. Apreender a existência e a dinâmica destas estratégias não permite mudar as causas profundas das desigualdades e das injustiças, nem sanar a evidente deficiência da atuação estatal, em todas as áreas ligadas de forma direta ou indireta às condições de saúde. Reconhecer esta realidade e os limites dos resultados aqui sistematizados é fundamental: tais características da sociedade brasileira, entre outras sociedades com o mesmo perfil históricoestrutural, são mais complexas e sua superação não se inscreve no nível da produção de conhecimentos.

Caberia, no entanto, refletir sobre este conhecimento sob um outro prisma, mais conforme ao seu próprio estatuto de interpretação e explicação de um dado objeto de pesquisa: passa-se a dispor da percepção de que as populações às quais se dirigem as políticas públicas, concebidas por peritos "de fora" - e que se pretendem portadoras de soluções adequadas às necessidades dos usuários - podem ser sujeitos de sua própria mudança e da resolução de seus problemas cotidianos. Aceitar a ideia de que as pessoas potencialmente beneficiárias de políticas públicas, até - e principalmente - as mais carentes, não são passivas, de que elas já atuam no dia a dia para procurar soluções, nos estreitos espaços de ação de que dispõem, abre a possibilidade para uma outra linha de desempenho da ação pública no domínio da saúde. Uma linha construída não exclusivamente por um saber vindo de cima para baixo, mas negociada a partir da própria experiência, das situações de vida e das estratégias postas em prática pelas diferentes camadas sociais da população.

Há muitos obstáculos sociais e políticos para operar essa reconversão. Mas os primeiros obstáculos que se têm de superar são aqueles que encontramos no quadro de nossa própria atuação como cientistas. Há de aceitar a ideia de que as "populações" geralmente consideradas como objetos de estudo são também sujeitos de sua historicidade, que têm sua própria experiência dos problemas que pretendemos conhecer e contribuir para resolver. Até nas situações mais desesperadas, continuam lutando para construir um futuro. Se são sujeitos, temos que considerá-los como parceiros: nossa postura em relação à produção de conhecimento tem, então, de partir da perspectiva da cumplicidade e da reciprocidade, o que tem implicações sobre as práticas de pesquisa que vamos desenvolver. Somente esta mudança de perspectiva pode nos impulsionar a conseguir, de alguma forma, exercer influência sobre a definição das políticas públicas.

É isto que estamos procurando alcançar no quadro do Doutorado em Meio Ambiente e Desenvolvimento da UFPR, pela prática interdisciplinar e, em particular, pela busca de uma estreita colaboração entre as ciências sociais e todas as demais disciplinas que podem contribuir à análise dos problemas ligados às relações entre as sociedades e seu ambiente físico e natural. Outros programas de pesquisa interdisciplinares, no Litoral do Paraná e na Região Metropolitana, foram desenvolvidos ou estão em andamento, com metodologia mais ou menos aproximada à aqui apresentada.

No que se refere a Paranaguá, os resultados apresentados nestes trabalhos testemunham a fase inicial desta procura por uma nova prática de pesquisa. Isto foi apenas uma etapa. Desde então, outras pesquisas vêm se desenvolvendo na cidade com o objetivo de aprofundar, verificar e complementar os conhecimentos produzidos pelo primeiro programa de pesquisa e seus resultados serão apresentados ulteriormente. Isto não minora o interesse dos trabalhos reunidos neste livro: seu objetivo essencial foi o de ilustrar um esforço pioneiro para pôr em prática outras formas de produção de conhecimento na interface entre questões de desenvolvimento e questões ambientais. 